\title{
Efeito do tratamento com própolis de Scaptotrigona aff. postica sobre o desenvolvimento do tumor de Ehrlich em camundongos
}

\author{
Maria José A. M. Araújo, Richard P. Dutra, Graciomar C. Costa, Aramys S. Reis, Anne K. M. \\ Assunção, Silvana A. Libério, Márcia C. G. Maciel, Lucilene A. Silva, Rosane N. M. Guerra, \\ Maria N. S. Ribeiro, Flávia R. F. Nascimento"
}

Centro de Ciências Biológicas e da Saúde, Universidade Federal do Maranhão, Av. dos Portugueses s/n, Campus do Bacanga, 65085-580 São Luís-MA, Brasil.

\begin{abstract}
RESUMO: Neste trabalho foi investigado o efeito do extrato hidroalcoólico de própolis (EHP) de Scaptotrigona aff. postica sobre o desenvolvimento do tumor de Ehrlich na forma sólida, sobre a celularidade dos órgãos linfóides dos animais portadores de tumor, bem como, sobre a produção de óxido nítrico (NO) pelos macrófagos destes animais. Camundongos Swiss foram divididos em quatro grupos: controle, EHP 0,5; EHP 5 e EHP 50, os quais foram tratados por via intraperitoneal com dose única de solução salina $(\mathrm{NaCl} 0,9 \%) ; 0,5 ; 5$ ou $50 \mathrm{mg}$ de $\mathrm{EHP} / \mathrm{kg}$ de animal, respectivamente. Depois de $48 \mathrm{~h}$ do tratamento, os animais foram inoculados com $10^{5}$ células do tumor de Ehrlich nas patas. Os resultados mostraram que o tratamento com EHP nas doses de 5 e $50 \mathrm{mg} / \mathrm{kg}$ inibiu de forma significativa o desenvolvimento do tumor a partir do $6^{\circ}$ dia pós-inóculo quando comparado ao controle e ao EHP 0,5. Além disso, houve aumento significativo da celularidade do baço e da medula óssea nos grupos EHP 0,5 e EHP 5 em relação ao controle. A produção de NO estimulada com concanavalina A (ConA) apresentou uma significante diminuição nos grupos tratados com EHP em relação ao controle. Pode-se concluir que o tratamento com EHP apresentou efeito antitumoral quando administrado nas doses de 5 e $50 \mathrm{mg} / \mathrm{kg}$, o que pode estar relacionado com a sua composição química e com a inibição da produção de NO.
\end{abstract}

Unitermos: própolis, Scaptotrigona aff. postica, tumor de Ehrlich, abelhas sem ferrão, Meliponinae.

\begin{abstract}
Effect of propolis of Scaptotrigona aff. postica on the development of the tumor of Ehrlich in mice". It was investigated the effect of hydroalcoholic extract (HEP) of propolis from Scaptotrigona aff. postica on the solid Ehrlich tumor, on the tumor-bearing mice lymphoid organs and on the nitric oxide (NO) production. Swiss mice were divided in 4 groups: control, HEP 0.5; HEP 5 and HEP 50 that was treated by intraperitoneal route with a single dose of saline solution $(\mathrm{NaCl} 0.9 \%$ ) or 0.5 or 5 or $50 \mathrm{mg}$ of $\mathrm{HEP} / \mathrm{kg}$ body weight, respectively. After $48 \mathrm{~h}$ of treatment, the animals were inoculated with $10^{5}$ tumor cells in their footpad. The results showed that the treatment with HEP in the doses of 5 and $50 \mathrm{mg} / \mathrm{kg}$ inhibited the development of the tumor from the $6^{\text {th }}$ day post inoculums when compared to the control and to the HEP 0.5 groups. Besides, there was an increase of spleen and bone marrow cell number in HEP 0.5 and HEP 5 as compared to the control. Concanavalin A (ConA)-stimulated NO production was decreased in all HEP-treated groups when compared to the control. In conclusion, the treatment with HEP had an anti-tumor effect what may be related to its chemical composition and to the inhibition of NO production.
\end{abstract}

Keywords: propolis, Scaptotrigona aff. postica, Ehrlich tumor, stingless bee, Meliponinae.

\section{INTRODUÇ̃̃O}

As abelhas coletam resinas e bálsamos de diferentes partes de plantas e adicionam secreções mandibulares produzindo à própolis, uma goma resinosa e balsâmica de estrutura complexa contendo aproximadamente 50 a $55 \%$ de resinas e bálsamos, $30 \%$ de cera, $10 \%$ de óleos voláteis, $5 \%$ de pólen e $5 \%$ de outras substâncias, podendo variar de acordo com a flora da região e a espécie de abelha. Este material é utilizado pelas abelhas dentro da colméia para desinfetar os favos, revestir as paredes internas, embalsamar insetos mortos e proteger a entrada contra intrusos (Nogueira-Neto, 1997; Burdock, 1998; Castaldo \& Capasso, 2002; Cunha et al., 2004).

A própolis, o mel, a cera e o pólen são considerados os principais produtos das abelhas. A partir de trabalhos publicados principalmente nas décadas de 
80 e 90, a própolis de Apis mellifera L. vem recebendo especial atenção por suas várias propriedades biológicas, entre elas: antimicrobiana (Santos et al., 2002), antifúngica (Murad et al., 2002), antioxidante (Ahn et al., 2004), antitumoral (Orsolic et al., 2005a; b; Padmavathi et al., 2006), antiinflamatória, anestésica, cicatrizante (Reis et al., 2000).

A ação antitumoral sugerida para a própolis de A. mellifera L. pode estar relacionada à sua composição química, que inclui, dentre outros compostos, flavonóides, ácidos fenólicos e terpenos (Kimoto et al., 1999; Marcucci et al., 2001). Quercetina e galangina são flavonóides que têm sido identificados como promissores agentes antitumorais (Orsolic et al., 2005a; b). Compostos derivados do ácido cinâmico, como a artepilina $\mathrm{C}$, encontrados nesta própolis, apresentam alta toxicidade para células tumorais (Matsuno et al., 1997; Salatino et al., 2005) e o isolamento de diterpenos tem demonstrado atividade anti-tumoral (Salatino et al., 2005).

Estudos farmacológicos têm demonstrado que a própolis de $A$. mellifera aumenta a atividade das células Natural Killer (NK) inibindo o crescimento das células tumorais (Sforcin et al., 2002) e modula in vitro e in vivo a produção de óxido nítrico (NO) e a liberação de peróxido de hidrogênio $\left(\mathrm{H}_{2} \mathrm{O}_{2}\right)$ por macrófagos peritoneais (Orsi et al., 2000). O ácido cinâmico isolado da própolis atua tanto na imunidade inata quanto na imunidade adquirida, estimulando a proliferação de linfócitos e induzindo a produção de citocinas (Ivanovska et al., 1995). Ésteres de ácido caféico têm sido apontados como potentes inibidores da carcinogênese de colón humano (Burdock, 1998; Sforcin et al., 2002).

Dentre as abelhas existentes no Brasil, destacamse aquelas pertencentes à família Apidae e subfamília Meliponinae, mais conhecidas como abelhas indígenas sem ferrão. Estas abelhas misturam material resinoso das plantas com cera e terra, formando a geoprópolis (Kerr, 1987; Nogueira-Neto, 1997; Bankova et al., 1998; Castaldo \& Capasso, 2002), porém, algumas espécies como Scaptotrigona aff. postica, popularmente conhecida no Maranhão como "tubi”, não utilizam terra para a produção de própolis (Nogueira-Neto, 1997). O gênero Scaptotrigona distribui-se por toda a região neotropical e reúne espécies que constroem seus ninhos em cavidades pré-existentes (Silveira et al., 2002).

As pesquisas com própolis têm se concentrado principalmente nas abelhas africanizadas A. mellifera L., entretanto, poucos estudos tratam da própolis de abelhas indígenas sem ferrão (Bankova et al., 1998). A própolis de $S$. aff. postica tem sido utilizada popularmente na região de Barra do Corda, Maranhão, no tratamento de tumores e na cicatrização de feridas. Contudo, são escassos os estudos que comprovem as suas atividades biológicas e a sua composição química.

Assim, neste trabalho foi investigado o efeito do tratamento com extrato hidroalcoólico de própolis de
Scaptotrigona aff. postica sobre o desenvolvimento do tumor de Ehrlich na forma sólida, a celularidade dos órgãos linfóides e a produção de óxido nítrico em camundongos. Além disso, foi realizada uma abordagem química do extrato utilizado neste estudo.

\section{MATERIAL E MÉTODOS}

\section{Animais}

Foram utilizados vinte camundongos fêmeas da linhagem Swiss, com peso em torno de 25-30 g e idade entre 3 e 4 meses, fornecidos pelo Biotério Central da Universidade Federal do Maranhão (UFMA). Os animais foram mantidos sob condições ambientais padronizadas, alimentados com dieta balanceada e água ad libitum. A utilização dos animais obedeceu a princípios técnicos e éticos preconizados pelo Colégio Brasileiro de Experimentação Animal (COBEA, 2004) (nº 009283/200812).

\section{Coleta das amostras de própolis}

A própolis foi obtida na comunidade Cerâmica, no município de Barra do Corda (5³0'S e $45^{\circ} 14^{\prime} \mathrm{W}$ ), localizado na parte central do estado do Maranhão. Na região predomina o cerrado com resquícios de floresta amazônica (Freire-Filho et al., 2005). As amostras de própolis foram coletadas em junho de 2006 (fim da estação chuvosa), diretamente das colméias da abelha Scaptotrigona aff. postica (tubi), pelo meliponicultor Sr. Wilson Melo e foram levadas para a Universidade Federal do Maranhão (UFMA), onde foram mantidas sob refrigeração até a preparação do extrato.

\section{Preparação e abordagem química do extrato hidroalcoólico de própolis (EHP)}

A amostra de própolis (213 g) foi triturada em turbolizador e macerada em etanol $70 \%$, na proporção de 1:3, por $24 \mathrm{~h}$. O material foi filtrado, concentrado em evaporador rotativo e seco até peso constante, obtendo-se o extrato hidroalcoólico de própolis (EHP). As soluções para o tratamento dos animais foram obtidas pela ressuspensão do EHP em solução salina $(\mathrm{NaCl}$ 0,9\%). $\mathrm{O}$ EHP foi submetido à abordagem química para análise dos seguintes grupos: compostos fenólicos, cumarinas, terpenos, saponinas e alcalóides (Matos, 1997).

\section{Tratamento com EHP de própolis}

Os animais foram divididos em quatro grupos ( $n=5$ por grupo) denominados controle, EHP 0,5; EHP 5 e EHP 50, os quais foram tratados com doses únicas de solução salina $(\mathrm{NaCl} 0,9 \%) ; 0,5 ; 5$ ou $50 \mathrm{mg}$ de EHP/kg de animal, respectivamente. Todos os tratamentos foram 
feitos por via intraperitoneal (i.p.) $48 \mathrm{~h}$ antes do inóculo do tumor.

\section{Manutenção e inoculação do tumor de Ehrlich}

AscélulasdotumordeEhrlich,umadenocarcinoma mamário, foram mantidas na forma ascítica por meio de inoculações semanais de $10^{6}$ células por via i.p. em camundongos Swiss (Kleeb et al., 1999). Após excisão da parede abdominal, o fluido ascítico foi retirado com auxílio de seringa e agulha estéreis. As células tumorais foram contadas em câmara de Neubauer e a viabilidade foi determinada através do método de exclusão pelo corante azul de tripan. Após $48 \mathrm{~h}$ do tratamento com EHP, foram inoculadas $10^{5}$ células do tumor no coxim plantar das patas posteriores esquerdas de cada animal. O desenvolvimento tumoral foi avaliado pela mensuração da espessura das patas, com auxílio de um paquímetro digital, a cada dois dias até o $24^{\circ}$ dia, quando os animais foram sacrificados e suas patas foram amputadas e pesadas.

\section{Obtenção das células da cavidade peritoneal}

Após o sacrifício, a cavidade peritoneal foi lavada com $5 \mathrm{~mL}$ de solução tamponada de fosfato (PBS) estéril. As suspensões celulares obtidas através de aspiração com seringa e agulha foram contadas e ajustadas para a concentração de $2 \times 10^{6}$ células $/ \mathrm{mL}$ para a realização do ensaio de produção de NO.

\section{Obtenção e contagem das células dos linfonodos poplíteos, do baço e da medula óssea}

Os linfonodos poplíteos das patas esquerda (linfonodo drenante) e direita (linfonodo não drenante) foram retirados, pesados e triturados em $1 \mathrm{~mL}$ de PBS, sendo as suspensões celulares diluídas 100x em PBS para a realização das contagens. Os baços foram retirados, pesados e triturados em $5 \mathrm{~mL}$ de PBS e as suspensões celulares foram mantidas em banho de gelo e diluídas 50x em PBS para contagem. Para obtenção das células da medula óssea, o fêmur da pata esquerda foi perfundido com $1 \mathrm{~mL}$ de PBS. Foram retirados $90 \mu \mathrm{L}$ das suspensões celulares obtidas dos respectivos órgãos. As células foram fixadas e coradas em $10 \mu \mathrm{L}$ de cristal violeta $(0,05 \%)$ dissolvido em ácido acético $30 \%$. As contagens celulares foram realizadas em câmara de Neubauer, com auxílio de microscópio ótico de luz comum.

\section{Produção de óxido nítrico (NO)}

A produção de NO foi mensurada através da medida de nitritos nos sobrenadantes das culturas de células peritoneais (Ding et al., 1988). Alíquotas de $100 \mu \mathrm{L}$ da suspensão de células peritoneais, na concentração de $2 \mathrm{x}$ $10^{6}$ células/mL de meio RPMI 1640 (Sigma) suplementado com $2 \mathrm{mM}$ de L-glutamina (Sigma), $23 \mathrm{mM}$ de L-asparagina (Sigma), 0,1 mM de ácido pirúvico (Sigma), $1 \mathrm{mM}$ de ácido fólico (Sigma), $1 \%$ de estreptomicina $(100 \mu \mathrm{g} / \mathrm{mL}$, Merck), penicilina G (100 U/mL, Sigma) e 10\% de soro fetal bovino (Sigma), foram transferidas para placa de 96 poços de fundo chato em quadruplicata e em dois poços de cada quadruplicata foram adicionados $5 \mu \mathrm{g} / \mathrm{mL}$ de concanavalina A (Con A) como estímulo in vitro.

As células foram cultivadas em placas por $48 \mathrm{~h} \mathrm{em}$ estufa contendo $5 \%$ de $\mathrm{CO}_{2}$. Ao final desse período foram transferidos $50 \mu \mathrm{L}$ dos sobrenadantes para outra placa aos quais foram adicionados $50 \mu \mathrm{L}$ de reagente de Griess $(1 \%$ de sulfanilamida $/ 0,1 \%$ de dihidrocloreto de naftileno $/ 2,5 \%$ de ácido orto-fosfórico) à temperatura ambiente por 10 min. A absorvância foi determinada em leitor de ELISA, com filtro de $540 \mathrm{~nm}$, com branco constituído por meio RPMI mais reagente de Griess. Os resultados obtidos em densidade óptica foram transformados em $\mu \mathrm{M}$ de NO2-, mediante equação de regressão linear com base em uma curva padrão feita com concentrações conhecidas de nitrito de sódio $\left(5,10,30\right.$ e $60 \mu \mathrm{M}$ de $\left.\mathrm{NO}_{2}{ }^{-}\right)$.

\section{Análise estatística}

Os procedimentos estatísticos foram realizados com auxílio do Software Graph Pad Prism, versão 4.0, por análise de variância (ANOVA), seguido do teste TukeyKramer, sendo o nível de significância de 5\%. Os dados foram expressos com a média \pm erro padrão da média (E.P.M.) de cinco animais por grupo.

\section{RESULTADOS}

\section{Prospecção química do EHP}

O rendimento do processo extrativo da amostra de própolis de Scaptotrigona aff. postica obtido por maceração em etanol a $70 \%$ foi de $9 \mathrm{~g}(4 \%)$. A abordagem química do EHP indicou a presença de substâncias principalmente das classes dos terpenos e cumarinas.

\section{Efeito do EHP sobre o desenvolvimento do tumor de Ehrlich}

O tratamento com EHP não induziu alterações significativas no desenvolvimento do tumor de Ehrlich na forma sólida até o $4^{\circ}$ dia pós-inóculo. Entretanto, a partir do $6^{\circ}$ dia pôde-se observar uma evolução do tumor no grupo controle e no grupo EHP 0,5, enquanto nos grupos EHP 5 e EHP 50 não ocorreu nenhuma alteração na espessura das patas até o $24^{\circ}$ dia, quando os animais foram sacrificados. Houve diferença significativa nos grupos EHP 5 e EHP 50 a partir do $6^{\circ}$ dia até o $24^{\circ}$ dia pós-inóculo quando comparados ao controle e ao EHP 0,5. Com relação ao EHP 50, a diferença não foi significante somente no $18^{\circ} \mathrm{e}$ $24^{\circ}$ dias pós-inóculo (Figura $1 \mathrm{~A}$ ). O peso das patas no $24^{\circ}$ 
dia não refletiu o observado com a mensuração da espessura, pois não houve diferença estatística entre os grupos (Figura 1B).

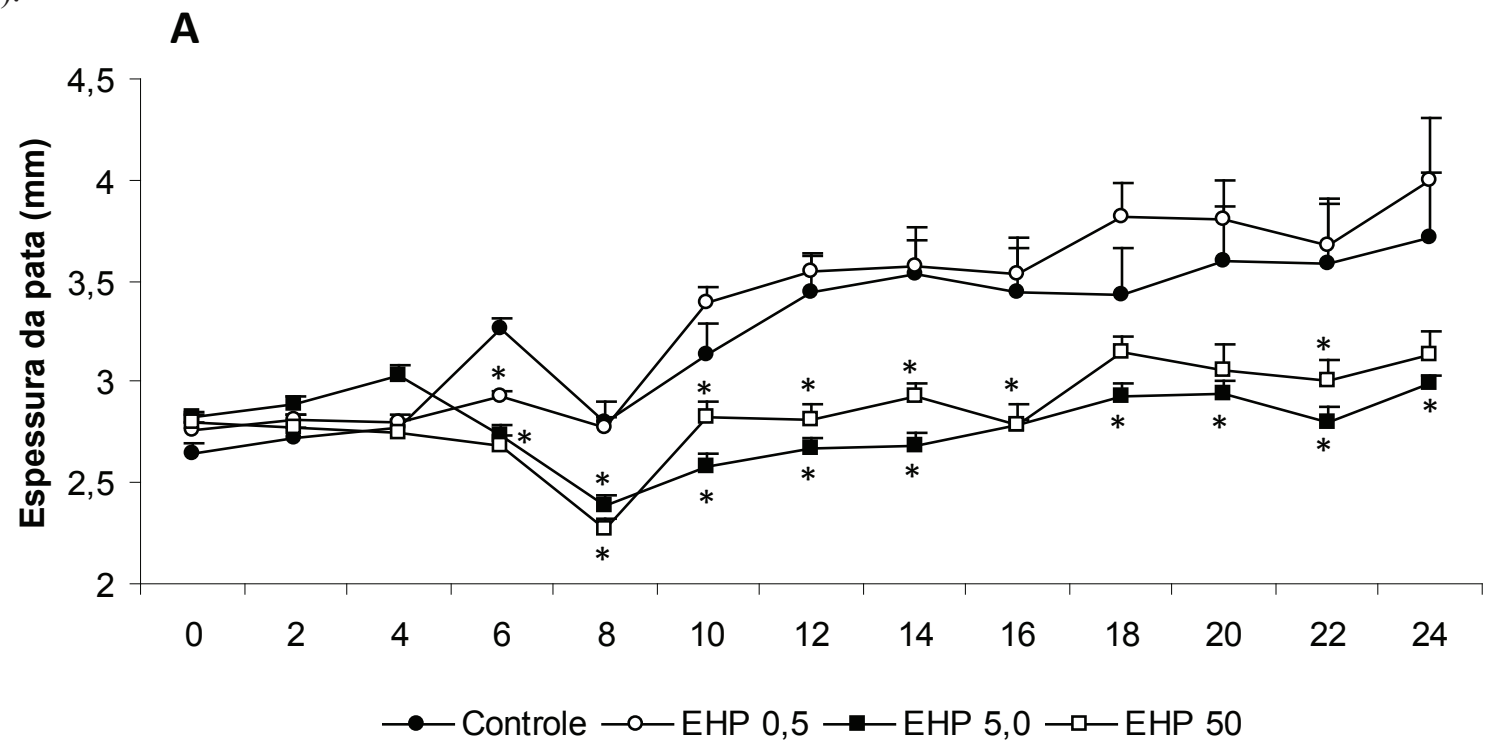

B

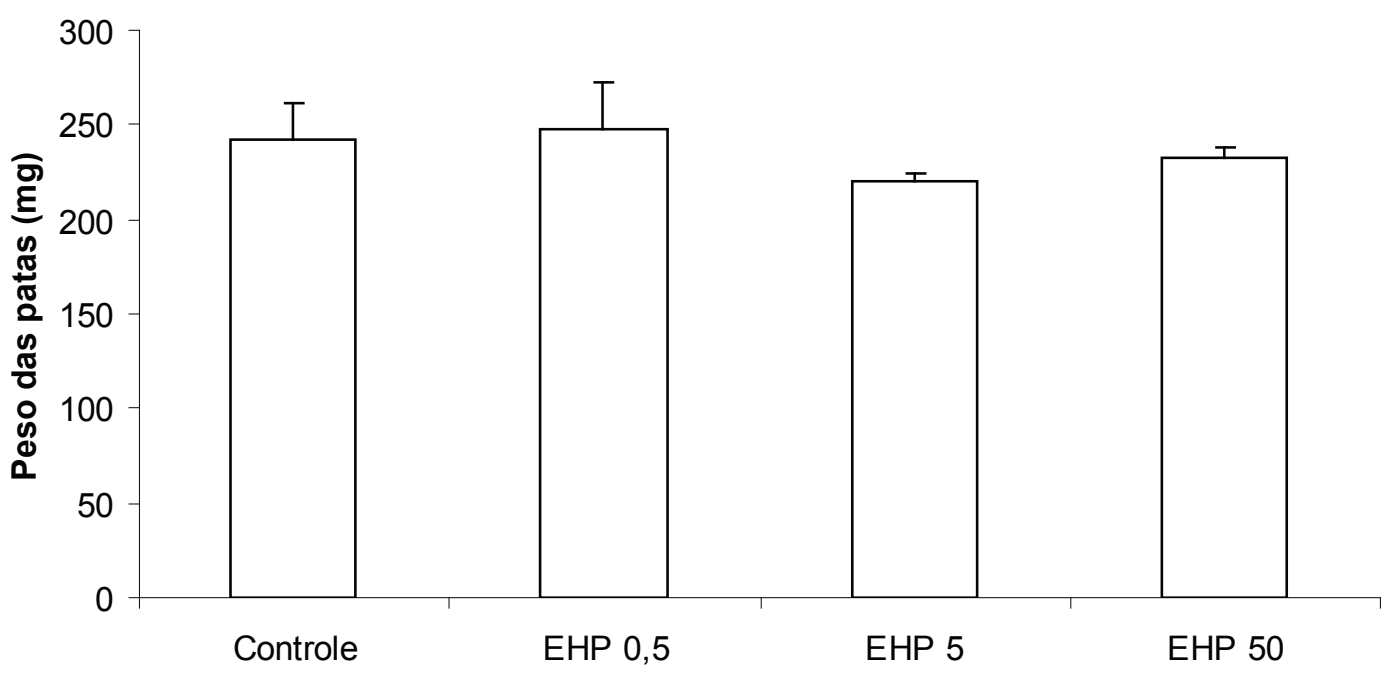

Figura 1. Efeito do tratamento com extrato hidroalcoólico de própolis (EHP) de Scaptotrigona aff. postica sobre o desenvolvimento do tumor de Ehrlich na forma sólida. Camundongos Swiss foram tratados com EHP em doses únicas de 0,5; 5 e $50 \mathrm{mg} / \mathrm{kg}$ por via i.p. A mensuração da espessura das patas foi realizada a cada dois dias com um paquímetro digital (A). Após 24 dias, os animais foram sacrificados e as patas foram amputadas e pesadas (B). Os dados representam a média \pm E.P.M. de cinco animais por grupo. ${ }^{*} p<0,05$ em relação ao grupo controle.

\section{Efeito do EHP sobre a celularidade dos órgãos linfóides}

O tratamento com EHP nas doses de 5 e $50 \mathrm{mg} /$ $\mathrm{kg}$ reduziu significativamente o número de células do linfonodo poplíteo drenante (Figura 2A), mas aumentou o número de células do linfonodo poplíteo não drenante (Figura 2B) quando comparados com o grupo controle e com o grupo EHP 0,5. Com relação ao número de células do baço e da medula óssea, ocorreu aumento significativo nos grupos EHP 0,5 e EHP 5 em relação ao controle. Por outro lado, ocorreu uma diminuição da celularidade no grupo EHP 50 em relação ao EHP 0,5 e EHP 5 (Figuras 2C e 2D).

Finalmente, a análise do número de células do peritônio revelou aumento significativo no grupo EHP 50 em relação ao grupo EHP 0,5 (Figura 3). 

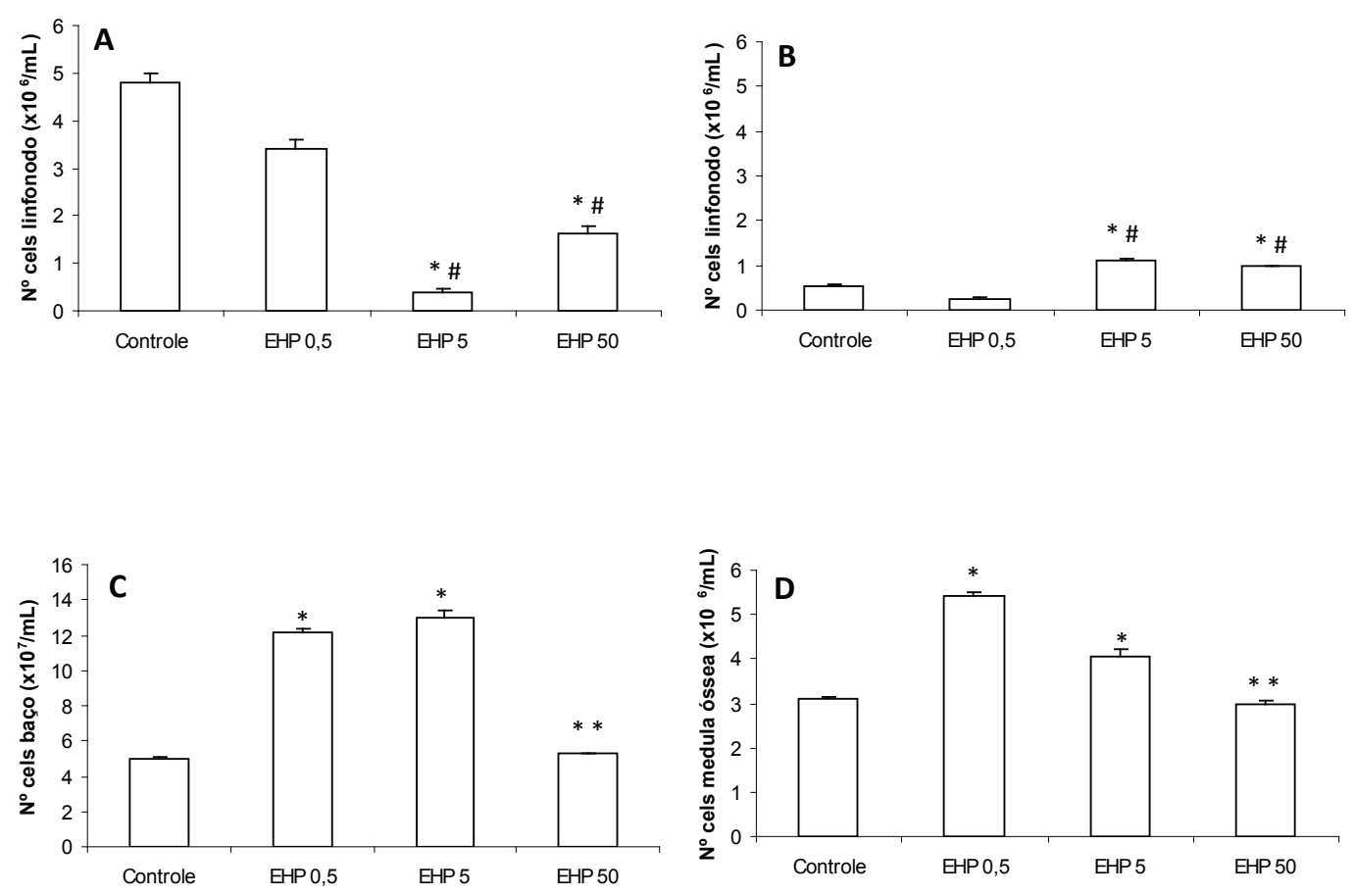

Figura 2. Efeito do tratamento com EHP de Scaptotrigona aff. postica sobre a celularidade dos órgãos linfóides. Camundongos Swiss foram tratados com EHP em doses únicas de 0,5; 5 e $50 \mathrm{mg} / \mathrm{kg}$ por via i.p. Após 24 dias, os animais foram sacrificados e as células do linfonodo poplíteo drenante (A), não drenante (B), do baço (C) e da medula óssea (D) foram contadas. Os dados representam a média E.P.M. de cinco animais por grupo. ${ }^{*} p<0,05$ em relação ao controle, $\# p<0,05$ em relação ao EHP 0,5 e $* * p<0,05$ em relação ao EHP 0,5 e EHP 5.

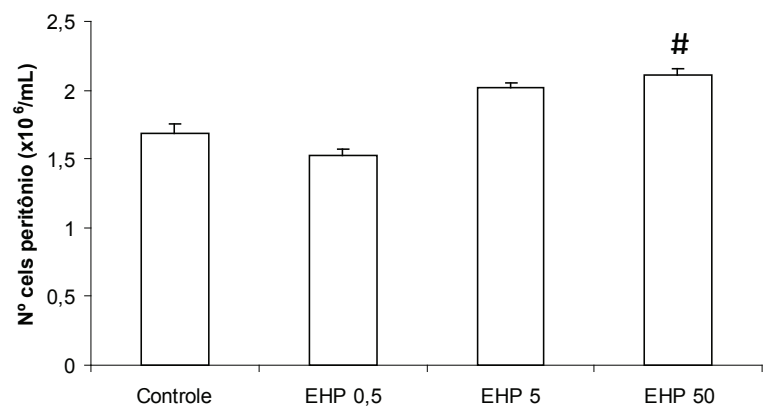

Figura 3. Efeito do tratamento com EHP de Scaptotrigona aff. postica sobre a celularidade do peritônio. Camundongos Swiss foram tratados com EHP em doses únicas de 0,$5 ; 5$ e $50 \mathrm{mg} /$ $\mathrm{kg}$ por via i.p. Após 24 dias, os animais foram sacrificados $\mathrm{e}$ as células peritoneais foram contadas. Os dados representam a média \pm E.P.M. de cinco animais por grupo. $\# p<0,05$ em relação ao EHP 0,5 .

\section{Efeito do EHP sobre a produção de óxido nítrico (NO)}

O tratamento com EHP nas três doses $(0,5 ; 5$ e $50 \mathrm{mg} / \mathrm{kg}$ ) não alterou significativamente a produção espontânea de NO em relação ao controle. Porém, a produção de NO induzida pelo estímulo in vitro com concanavalina A (Con A), foi inibida significativamente nos grupos tratados com EHP em relação ao controle (Figura 4).

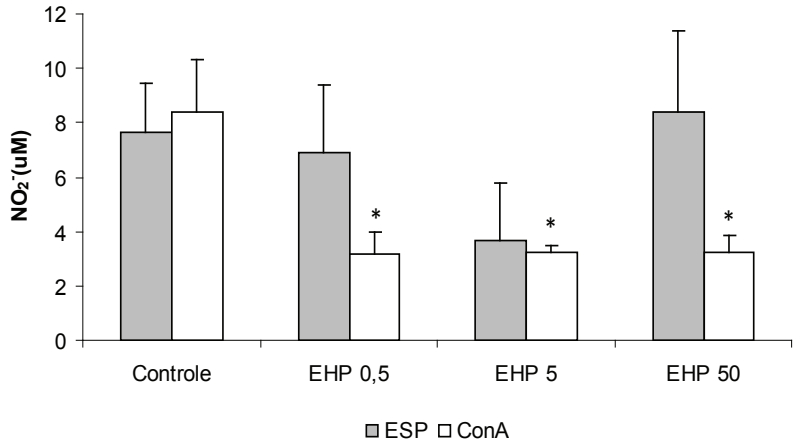

Figura 4. Efeito do tratamento com EHP de Scaptotrigona aff. postica sobre a produção de óxido nítrico. Camundongos Swiss foram tratados com EHP em doses únicas de 0,$5 ; 5$ e $50 \mathrm{mg} / \mathrm{kg}$ por via i.p. Após 24 dias, os animais foram sacrificados, as células peritoneais foram ajustadas para $2 \times 10^{6}$ células $/ \mathrm{mL}$ e colocadas em cultura por $48 \mathrm{~h}$ para avaliar a produção de NO espontânea (Esp.) ou estimuladas com Con A. Os dados representam a média \pm E.P.M. de cinco animais por grupo. ${ }^{*} p<0,05$ em relação ao controle.

\section{DISCUSSÃO}

A própolis é um produto apícola de enorme aplicabilidade na medicina tradicional desde os tempos antigos, sendo principalmente utilizada como um antisséptico e cicatrizante. Atualmente, tem sido considerada como um dos mais promissores produtos utilizados na quimioprevenção e tratamento de várias doenças, em especial na carcinogênese (Kimoto et al., 
1999; Orsolic et al., 2005a,b; Padmavathi et al., 2006).

$\mathrm{O}$ processo de carcinogênese apresenta vários estágios incluindo a iniciação, a promoção e a progressão do tumor (Almeida et al., 2005). Assim, o alvo de muitas pesquisas tem sido a descoberta de compostos naturais ou sintéticos que possam prevenir, retardar ou reverter o processo de carcinogênese (Orsolic et al., 2005a;b).

Os resultados demonstraram que o tratamento intraperitoneal com EHP de Scaptotrigona aff. postica, 48 $\mathrm{h}$ antes da inoculação do tumor nas patas dos camundongos inibiu a progressão do tumor a partir do $6^{\circ}$ dia pós-inóculo quando administrado com doses únicas de 5 e $50 \mathrm{mg} /$ $\mathrm{kg}$. Porém, o tratamento com a dose de $0,5 \mathrm{mg} / \mathrm{kg}$ não induziu efeito inibitório no desenvolvimento do tumor, apresentando crescimento semelhante ao grupo controle. Estes dados corroboram os de Kimoto et al. (1999), que demonstraram que a incidência e multiplicação de carcinomas mamários em ratos foi significativamente diminuída pela administração de própolis de Apis mellifera na dieta dos animais por 33 semanas.

Uma possível explicação para resultados obtidos neste trabalho seria o efeito antitumoral de determinados constituintes da própolis de Scaptotrigona aff. postica. como di- e triterpenos, atuando isoladamente ou em sinergismo.

Flavonoides são conhecidos por afetar a proliferação, diferenciação e apoptose de células cancerígenas (Kuo, 1996). Já polifenólicos, como o ácido caféico e o cafeato de feniletila, que são os dois componentes mais ativos da própolis de Apis mellifera, afetam o crescimento do tumor através da inibição da síntese de DNA e exercem efeitos antitumorais através da indução de apoptose das células tumorais (Orsolic et al., 2005b). O aumento dos índices de apoptose tem sido associado à inibição do crescimento de células potencialmente oncogênicas (Campisi, 2005), porém, o mecanismo envolvido na ação antitumoral da própolis não está completamente elucidado.

Com relação ao efeito da própolis sobre os órgãos linfóides, foi observado que o tratamento com EHP nas doses de 5 ou $50 \mathrm{mg} / \mathrm{kg}$ provocou uma significante redução do número de células no linfonodo poplíteo drenante quando comparado aos grupos controle e EHP 0,5 . Quanto ao número de células do linfonodo poplíteo não drenante, ocorreu um efeito oposto, pois o número de células aumentou significativamente nos grupos tratados com estas mesmas doses em relação aos grupos controle e EHP 0,5. Pode-se inferir que o tratamento com EHP nas doses de 5 e $50 \mathrm{mg} / \mathrm{kg}$ induziu uma diminuição da proliferação de células linfóides no linfonodo poplíteo drenante. Isto pode estar associado com a produção de NO, pois este metabólito produzido por células tumorais pode limitar a proliferação e infiltração de leucócitos (Wink et al., 1998).

Um significativo aumento de células também foi observado no baço e na medula óssea de animais tratados com EHP nas doses de 0,5 e $5 \mathrm{mg} / \mathrm{kg}$ em relação ao controle, mostrando que estas doses induziram aumento da produção de células imunológicas periféricas e precursoras.

Segundo Scheller et al. (1988), a atividade imunoestimulante da própolis de A. mellifera pode estar associada com a ativação de macrófagos e com o aumento da capacidade fagocítica destas células. O extrato de própolis estimula macrófagos peritoneais a produzirem citocinas, como interferon-gamma (IFN- $\gamma$ ), fator alfa de necrose tumoral (TNF- $\alpha$ ) e interleucina-12 (IL-12), que atuam sobre células NK, aumentando sua atividade tumoricida (Sforcin et al., 2002). Células NK, assim como macrófagos, são células fundamentais na imunidade inata, mostrando atividade citotóxica para diversos tipos de tumores (Boyiadzis et al., 2006).

Para investigar se o efeito do EHP estaria relacionado com a produção de $\mathrm{NO}$, as culturas de células peritoneais foram analisadas. Em nossos resultados, observamos que a produção espontânea de NO foi induzida pelo crescimento tumoral, pois tanto no grupo controle quanto nos grupos tratados com o EHP nas três doses, a produção deste metabólito foi observada. Entretanto, a produção de NO estimulada por Con A foi menor nos grupos tratados com EHP quando comparados ao controle. Estes resultados estão de acordo com alguns trabalhos que mostram que extratos de própolis inibem a produção de NO por macrófagos estimulados com lipopolissacarídeos (LPS) bacterianos ou IFN- $\gamma$, dependendo da dose (Moriyasu et al., 1994; Orsi et al., 2000). A produção de NO em tumores sólidos experimentais pode facilitar a permeabilidade vascular e o rápido crescimento do tumor (Maeda \& Akaike, 1998), enquanto uma baixa produção deste metabólito pode causar um efeito oposto. Portanto, a inibição do NO nos grupos tratados com EHP e estimulados com Con A, poderia estar relacionada com a inibição do crescimento tumoral. Estes resultados estão de acordo com as investigações realizadas por Ivanovska et al. (1993) e Orsi et al. (2000) que sugeriram que os constituintes químicos da própolis de $A$. mellifera, atuam nos macrófagos ora inibindo, ora estimulando a produção de peróxido de hidrogênio e de NO.

Com os dados obtidos aqui, pode-se sugerir que o tratamento com EHP de Scaptotrigona aff. postica apresentou efeito antitumoral, quando administrado nas doses de 5 e $50 \mathrm{mg} / \mathrm{kg}$. Este possível efeito pode estar relacionado com a composição química da própolis em estudo e com a inibição da produção de NO. É importante ressaltar que ao diferente de outros trabalhos utilizando tratamento prolongado e altas doses de extrato ou compostos isolados da própolis de A. mellifera, foram administradas aqui doses únicas e pequenas do EHP, o que mostra um efeito bastante eficaz.

Este estudo reúne os primeiros relatos da atividade antitumoral da própolis de Scaptotrigona aff. postica. Estes resultados indicam que esta própolis pode ser importante para o controle do crescimento tumoral em modelos de 
tumores sólidos experimentais. Estudos posteriores serão realizados com o objetivo de caracterizar os constituintes bioativos envolvidos na atividade antitumoral desta própolis.

\section{AGRADECIMENTOS}

Ao CNPq, ao Banco do Nordeste (BNB), à CAPES e à Fundação de Amparo de Pesquisa do Maranhão (FAPEMA) pelo auxílio financeiro e pelas bolsas concedidas. À Profa. Dra. Gisele Garcia Azevedo pelas sugestões feitas na preparação deste manuscrito. Os autores agradecem a Bruno P. Ribeiro, Walmir C. Aragão Filho e Sanara M. Sousa pelo apoio técnico.

\section{REFERÊNCIAS}

Ahn MR, Kumazawa S, Hamasaka T, Bang K.S, Nakayama T 2004. Antioxidant activity and constituents of propolis collected in various areas of Korea. J Agric Food Chem 52: 7286-7292.

Almeida VL, Leitão A, Reina LCB, Montanari CA, Donnici CL, Lopes MTP 2005. Câncer e agentes antineoplásicos, ciclo-celular específicos e ciclo-celular não específicos que interagem com o DNA: uma introdução. Quim Nova 28: 118-129.

Bankova VS, Christov R, Marcucci MC, Popov S 1998. Constituents of Brazilian geopropolis. Z Naturforsch 53: 402-406.

Boyiadzis M, Foon KA, Herberman RB 2006. NK cells in cancer immunotherapy: three decades of discovery. Discov Med 6: 243-248.

Burdock GA 1998. Review of the biological properties and toxicity of bee propolis (propolis). Food Chem Toxicol 36: 347-363.

Campisi J 2005. Aging, tumor suppression and cancer: high wireact! Mech Agein Dev 126: 51-58.

Castaldo S, Capasso F 2002. Propolis, an old remedy used in modern medicine. Fitoterapia 73: 1-6.

Colégio Brasileiro de Experimentação Animal 2004. Legislação e Ética. Resolução 592. Disponível em: http://www.cobea. org.br/etica.htm. Acesso em 29 de janeiro de 2007.

Cunha IBS, Sawaya ACHF, Caetano FM, Shimizu MT, Marcucci MC, Drezza FT, Povia GS, Carvalho PO 2004. Factors that influence the yield and composition of brazilian propolis extracts. J Braz Chem Soc 15: 964-970.

Ding AH, Nathan CF, Stuehr DJ 1988. Release of reactive nitrogen intermediates and reactive oxygen intermediates from mouse peritoneal macrophages. J Immunol 141: 2407-2412.

Freire-Filho FR, Rocha MM, Ribeiro VQ, Lopes ACA 2005. Adaptabilidade e estabilidade produtiva de feijão-caupi. Cien Rural 35: 24-30.

Ivanovska N, Stefanova Z, Valeva V, Neychev H 1993. Immunomodulatory action of própolis: VII. A comparative study on cinnamic and caffeic acid lysine derivatives. Comptes-rendus de L'Académie Bulgare des Sciences 46: 115-117.

Ivanovska N, Neychev H, Stefanova Z, Bankova V, Popov $S$ 1995. Influence of cinnamic acid on lymphocyte proliferation, cytokine release and Klebsiella infection in mice. Apidologie 26: 73-81.

Kerr WE 1987. Abelhas indígenas brasileiras (Meliponíneos) na polinização e na produção de mel, pólen, geoprópolis e cera. Informe Agropecuário 13: 15-22.

Kimoto N, Hirose M, Kawabe M, Satoh T, Miyataka H, Shirai T 1999. Post-initiation effects of a super critical extract of propolis in a rat two-stage carcinogenesis model in female F344 rats. Cancer Lett 147: 221-227.

Kleeb SR, Rizzo MS, Dagli MLZ, Frussa-Filho R 1999. Haloperidol increases spreading and nitric oxide production in macrophages from tumor bearing mice: a possible mechanism for its antitumoral effect. Int $J$ Immunopharmacol 21: 575-580.

Kuo SM 1996. Antiproliferative potency of structurally distinct dietary flavonoids on human colon câncer cells. Cancer Lett 110: 41-48.

Maeda H, Akaike T 1998. Nitric oxide and oxygen radicals in infection, inflammation, and cancer. Biochem 63: 854865.

Matos FJA 1997. Introdução à Fitoquímica Experimental. Fortaleza: Edições UFC.

Matsuno T, Jung S-K, Matsumoto Y, Santo M, Monkawa I 1997. Preferential cytotoxicity to tumor cells of 3,5-diprenyl4-hydroxycinnamic acid (artepillin C) isolated from propolis. Anticancer Res 17: 3565-3568.

Marcucci MC, Ferreres F, Garcia-Viguera C, Bankova VS, De Castro SL, Dantas AP, Valente PHN, Paulino N 2001. Phenolic compounds from Brazilian propolis with pharmacological activities. J Ethnopharmacol 74: 105112.

Moriyasu J, Arai S, Motoda R, Kurimoto M 1994. In vitro activation of mouse macrophage by própolis extract powder. Biotherapy 8: 364-365.

Murad JM, Calvi SA, Soares AMVC, Bankova V, Sforcin JM 2002. Effects of propolis from Brazil and Bulgaria on fungicidal activity of macrophages against Paracoccidioides brasiliensis. J Ethnopharmacol 79: 331-334.

Nogueira-Neto P 1997. A criação de abelhas indígenas sem ferrão. São Paulo, Ed. Nogueirapis, 446p.

Orsi RO, Funari SRC, Soares AMVC, Calvi SA, Oliveira SL, Sforcin JM, Bankova V 2000. Immunomodulatory action of propolis on macrophage activation. J Venom Anim Toxins 6: 205-219.

Orsolic N, Kosalec I, Basic I 2005a. Synergystic antitumor effect of polyphenolic components of water soluble derivative of propolis against Ehrlich ascites tumour. Biol Pharm Bull 28: 694-700.

Orsolic N, Kosalec I, Basic I 2005b. Effects of local administration of propolis and its polyphenolic compounds on tumor formation and growth. Biol Pharm Bull 28: 1928-1933. 
Padmavathi R, Senthilnathan P, Sakthisekaran, D 2006. Therapeutic effect of propolis and paclitaxel on hepatic phase I and II enzymes and marker enzymes in dimethylbez(a)anthracene-induced breast cancer in female rats. Comp Biochem Physiol 143: 349-354.

Reis CMF, Carvalho JCT, Caputo LRG, Patrício KCM, Barbosa MVJ, Chieff AL, Bastos JK 2000. Atividade antiinflamatória, antiúlcera gástrica e toxicidade subcrônica do extrato etanólico de própolis. Rev Bras Farmacogn 9/10: 43-52.

Salatino A, Teixeira EW, Negri G, Message D 2005. Origin and chemical variation of Brazilian propolis. Evid Based Complement Alternat Med 2: 33-38.

Santos FA, Bastos EMA, Uzeda M, Carvalho MAR, Farias LM, Moreira ESA, Braga FC 2002. Antibacterial activity of Brazilian propolis and fractions against oral anaerobic bacteria. J Ethnopharmacol 80: 1-7.

Scheller S, Gazda G, Pietsz G, Gabrys J, Szumlas J, Eckert J, Shani J 1988. The ability of ethanolic extract of propolis to stimulate plaque formation in immunized mouse spleen cells. Pharmacol Res Commun 20: 323-328.

Sforcin JM, Kaneno R, Funari SRC 2002. Absence of seasonal effect on the immunomodulatory action of Brazilian propolis on natural killer activity. J Venom Anim Toxins 8: 19-29.

Silveira FA, Melo GAR, Almeida EAB 2002. Abelhas brasileiras: sistemática e identificação. Belo Horizonte: Composição e Arte, 253p.

Wink DA, Vodovotz Y, Laval J, Dewhirst MW, Mitchell JB 1998. The multifaceted roles of nitric oxide in cancer. Carcinogenesis 19: 711-721. 